\title{
Flowering Syndrome-Hybrid Performance Relationship in Maize 2- Grain Yield and Yield Components
}

\author{
H. A. Alkhazaali, M. M. Elsahookie, F. Y. Baktash \\ Department of Field Crop Sci., Coll. of Agric., University of Baghdad, Baghdad, Iraq
}

Email address:

haider_0068@yahoo.com (H. A. Alkhazaali)

\section{To cite this article:}

H. A. Alkhazaali, M. M. Elsahookie, F. Y. Baktash. Flowering Syndrome-Hybrid Performance Relationship in Maize 2- Grain Yield and Yield Components. International Journal of Applied Agricultural Sciences. Vol. 3, No. 3, 2017, pp. 72-77. doi: 10.11648/j.ijaas.20170303.13

Received: January 26, 2017; Accepted: February 10, 2017; Published: April 26, 2017

\begin{abstract}
A field experiment was conducted for 4 seasons on the farm of the Dept. of Field Crop Sci., Coll. of Agric., Univ. of Baghdad in spring and fall plantings in 2014 and 2015. That was to determine the relationship of hybrid performance in maize (Zea mays L.) crosses with early and late selects of inbreds. Four inbreds; Zm19, Zm32, Zm51, and Zm61 were grown and the very early and very late silking plants were selected and selfed for propagation in the first two seasons. The third season involved growing the selects and top-crossing with early and late inbreds ( $\mathrm{Zm} 60$ and $\mathrm{Zm} 21)$. The sixteen crosses were planted in season 4 in RCBD of 3 replicates in population density of $83^{\prime} 000$ plants. ha ${ }^{-1}$. The cross $(\mathrm{Zm} 19 x \mathrm{xm} 60)$ resulted from early select of $\mathrm{Zm} 19$ gave significantly higher grain yield $\left(10.52 \mathrm{t}^{\mathrm{ga}} \mathrm{a}^{-1}\right)$ compared to its late counterpart $\left(8.19 \mathrm{t}\right.$. ha $\left.\mathrm{h}^{-1}\right)$. The same cross gave higher grain yield than late $\mathrm{Zm} 19$ crossed to late inbred $(\mathrm{Zm} 21)\left(6.64 \mathrm{t}\right.$. ha $\left.{ }^{-1}\right)$. Early selects on inbreds crossed to testers showed significant differences in kernel growth rate (KGR), kernel filling duration (KFD) and kernel weight. Values of KGR ranged between $3.2-3.5 \mathrm{~g}$. plant ${ }^{-1}$. $\mathrm{d}^{-1}$, KFD between $35-38 \mathrm{~d}$, and kernel weight between $228-294 \mathrm{mg}$. kernel ${ }^{-1}$. It was concluded that selection on maize inbred populations creates new variations in traits lead to higher grain yield hybrids. Other traits such as ear length, kernel. ear ${ }^{-1}$, and kernel weight could be good candidates for selection on inbreds that could help developing new high grain yield hybrids.
\end{abstract}

Keywords: Days of Kernel Filling, Epigenetic, Grain Yield, Kernel Growth Rate, QTL, Selection on Inbreds

\section{Introduction}

The transition process from vegetative to reproductive stage in plants is of prime importance to productivity, since this process is influenced by genetic and environmental factors [1]. The time of flowering is a complex syndrome that shows a wide range ( $35-120$ days) in maize [2]. Time of flowering in plants could be related to some phenotypic traits such as plant height, leaf area, and seed filling [3]. Several researchers $[4,5,6]$ reported over 60 QTL in maize and Arabidopsis, and that each QTL in maize controls a part of phenotypic character [5]. In maize, there are genes control flowering, but still sharing control on other traits $[5,7,8]$. Durand et al. [9] worked on selection for flowering time in maize population and found $4 \mathrm{~d}$ interval between flowering time of two selected groups. On the other hand, Chardon et al. [10] reported some mutations in maize flowering time, which was correlated with meristem differentiation from vegetative to reproductive stages.
Hybrid vigour in maize and other crops is of wide international uses and highly important in world food production. However, this phenomenon is still not well understood. Meanwhile, hybrid vigour counts on wide genetic diversity between crossed parents [11]. Molecular discoveries obtained in the last years are considered as a beginning to understand this phenomenon $[12,13]$. Allelic interactions of parents are well-thought-out responsible on growth rate, biotic and abiotic tolerance in hybrids [14]. The regulative actions of epigenetic effect are considered so important in understanding the actions and interactions between DNA and siRNA in hybrid vigour activities of growth rate and phenotypic traits $[12,15,16,17,18]$. The objective of this trial was to discover the relationship between flowering syndrome (early and late flowering) selection on some maize inbreds populations and the performance of hybrid crosses resulted from those two selects by using two diverged inbreds in flowering time. 


\section{Materials and Methods}

A field experiment was applied on the farm of the Dept. of Filed Crops Sci, Coll. of Agric., Univ. of Baghdad in four seasons (spring and fall) in 2014 and 2015. Four maize inbreds $(\mathrm{Zm} 19, \mathrm{Zm} 32, \mathrm{Zm} 51$, and $\mathrm{Zm} 61)$ were grown and early and late silking plants were selected and selfed. In the second season, the eight groups of seeds were grown for propagation via selfing. In the third season, the seeds of the eight selected groups were grown and top-crossed to early silking inbred (Zm60) and to late silking inbred (Zm21). The sixteen crosses seeds were grown in the fourth season in RCBD of three replicates. Each plot consisted of six rows $\left(7.5 \mathrm{~m}^{2}\right)$ of $83^{\prime} 000$ plants. $\mathrm{ha}^{-1}$. Fertilizers used were 200 $\mathrm{kg} / \mathrm{ha}$ of each N, P and K. Fertilizers sources were urea, triple superphosphate, and potassium sulfate, respectively. Practices of weeding and irrigation were done as needed. Data were recorded on plants of the central four rows. Samples of 10 plants of each plot were taken to record data on agronomic traits as shown in the tables of this part and part 1 of the article published in this issue of this journal. Results obtained were tabulated and statistically analyzed.

\subsection{Rapid PCR Test}

RAPID polymerase Chain Reaction (PCR) test was conducted for some superior crosses in grain yield (Zm19xZm60 and Zm61xZm21 early and late flowering) to find out the nature of DNA bands of each group of the late and early flowering superior crosses, DNA was extracted from the seedlings of the above mentioned crosses and specific segments of DNA were amplified using 15 primers [19].

\subsection{PCR Requirements}

The main requirements of PCR are:

- Tag DNA Polymerase.

- DNA Primers, Deoxynucleosid triphosphates, which are nucleosides of (Deoxy Adenosine Triphosphate-dATP; Deoxy Thymosine Triphosphate-dTTP; Deoxy Guanosine Triphosphate-dGTP; and Deoxy Cytosine Triphosphate-dCTP).

- PCR buffer including $\mathrm{Mg}^{++}$.

- DNA template, Thermocycler.

- Other components [20].

\subsection{PCR Stages}

Three basic stages were identified in PCR reaction, which are repeated in each cycle of DNA replication cycles over a limited period of time [20]. The stages are:

1. Denaturation of the two strands of DNA: by raising the temperature of the reaction solution to $92-95^{\prime} \mathrm{C}$ for 3 to 5 minutes, the double helix of DNA will be melted apart to create single strand that will be a template to build a complementary segment of it.

2. Primer annealing: in this stage the temperature will be lowered to allow the primers to bind the single strand of
DNA template. The best primer binding temperatures vary but it is typically around $60^{\circ} \mathrm{C}$.

3. Extension; the last stage of PCR reaction, which includes adding dNTPs to the end of $\mathrm{OH}$ of the primer at the binding location with DNA template to produce new strand (a complementary DNA strand) to the sequence target. Best temperature required for this stage is $72^{\prime} \mathrm{C}$.

\section{Results and Discussion}

Kernel weight and number. $\mathrm{m}^{-2}$ :

Kernel weight is determined via size of source of metabolites and its efficiency to be converted into kernel components [21]. Kernels start developing after fertilization, continue in growth until dough stage and reach their final weight at time of physiologic maturity [22]. However, kernel weight is highly inherited in the genotype, and genotypes differ in this trait $[23,24,25]$. Those differences in final kernel weights of genotypes are related to system capacity constant in the genotype, which is associated with the traits contribute to dry matter accumulation [24, 26, 27]. Table 1 shows significant differences in kernel weights of crosses. The cross $[19 \times 60)$ showed significant difference between early and late silking select crosses.

Table 1. Kernel weight (mg) and kernels. $m^{-2}$ of crosses of early and late selects of maize inbreds obtained from crossing them with two testers (late $\mathrm{Zm} 21$ and early Zm60).

\begin{tabular}{|c|c|c|c|c|}
\hline \multirow{3}{*}{ Crosses } & \multicolumn{4}{|c|}{ Selected populations } \\
\hline & Early & Late & Early & Late \\
\hline & \multicolumn{2}{|c|}{ Kernel weight } & \multicolumn{2}{|c|}{ Kernel. $\mathbf{~ m}^{-2}$} \\
\hline $19 \times 21$ & 199 & 171 & 3328 & 3349 \\
\hline $32 \times 21$ & 208 & 191 & 3697 & 3839 \\
\hline $51 \times 21$ & 250 & 245 & 4037 & 4056 \\
\hline $61 \times 21$ & 217 & 240 & 4561 & 4565 \\
\hline $19 \times 60$ & 294 & 191 & 3591 & 4296 \\
\hline $32 \times 60$ & 244 & 205 & 4232 & 4513 \\
\hline $51 \times 60$ & 232 & 225 & 4317 & 4145 \\
\hline $61 \times 60$ & 228 & 215 & 4519 & 4758 \\
\hline \multicolumn{5}{|l|}{ lsd } \\
\hline $5 \%$ & 040 & & 847 & \\
\hline $10 \%$ & 030 & & 704 & \\
\hline
\end{tabular}

The cross $(32 \times 60)$ gave a significant difference in kernel weight at $\mathrm{p}=0.1$. Other select crosses were similar in kernel weights for early and late. On the other hand, early select cross of inbred $\mathrm{Zm} 19$ was significantly different when crossed with late $(\mathrm{Zm} 21)$ and early (Zm60) testers. Since the cross 19x21 gave $199 \mathrm{mg} / \mathrm{kernel}$ compared to $294 \mathrm{mg} / \mathrm{kernel}$ of the cross $19 \times 60$.

Number of kernels. $\mathrm{m}^{-2}$ of crosses were also significant as shown in Table1. Crosses in general were significantly different in this trait. However, early and late selects from inbred Zm19 crossed to early inbred tester (Zm60) showed significant difference in number of kernels. $\mathrm{m}^{-2}$. At the same time, these two selects did not give significant difference when crossed to late inbred tester ( $\mathrm{Zm} 21)$. The cross $19 \times 60$ gave 3591 and 4296 kernel. $\mathrm{m}^{-2}$ for late and early selects, 
respectively. As it will be shown later, this cross did not give higher grain yield. That could be due to low kernel growth rate and low number of days for kernel filling. Number of kernels. plant ${ }^{-1}$ or. $\mathrm{m}^{-2}$ is an important component in grain yield in all seed plants [24, 28, 29].

Days of kernel filling and kernel growth rate:

Days of kernel filling (DKF) and kernel growth rate (KGR) are the components that determine the final kernel weight [20]. Genetic and growth variables are controlling DKF and KGR. However, it could be possible to manage DKF by optimizing dates of planting, fertilization, and irrigation. Tollenaar et al. [31] reported that grain yield of maize could be increased by $0.37 \mathrm{t}$. ha ${ }^{-1}$ for each extra day of DKF. On the other hand, Greaves et al. [15] described that some maize early hybrids gave higher grain yield because of high KGR. Data of Table 2 shows that all early and late select crosses gave significant differences in DKF except the cross $51 \times 21$ that gave $38 \mathrm{~d}$ for both late and early select crosses.

Table 2. Kernel growth rate (KGR) g. plant ${ }^{-1} . d^{-1}$ and days of kernel filling $(D K F)$ of maize crosses resulted from early and late selects of inbreds crossed by two testers (late Zm21 and early Zm60).

\begin{tabular}{lllll}
\hline \multirow{2}{*}{ Crosses } & \multicolumn{4}{l}{ Selected populations } \\
\cline { 2 - 5 } & Early & Late & Early & Late \\
\cline { 2 - 5 } & KGR & & DKF & \\
\hline $19 \times 21$ & 2.1 & 1.9 & 38 & 35 \\
$32 \times 21$ & 2.3 & 2.4 & 40 & 36 \\
$51 \times 21$ & 3.2 & 3.1 & 38 & 38 \\
$61 \times 21$ & 3.0 & 3.7 & 40 & 35 \\
$19 \times 60$ & 3.4 & 2.9 & 37 & 34 \\
$32 \times 60$ & 3.3 & 3.2 & 38 & 35 \\
$51 \times 60$ & 3.1 & 3.1 & 38 & 36 \\
$61 \times 60$ & 3.3 & 3.5 & 37 & 34 \\
1 sd & & & & \\
$5 \%$ & 0.7 & & 2 & \\
$10 \%$ & 0.6 & & 2 & \\
\hline
\end{tabular}

Early selects of inbreds when crossed to early or late inbred showed about 3-5 d longer time for DKF. If other related yield components are remained the same, grain yield will be significantly increased.

In general, we can note from Table 2 that crosses of longer DKF had lower KGR, but this is not a rule. The best two opposite crosses in this trend are $61 \times 21$ and $19 \times 60$, since they had 40, $35 \mathrm{DKF}$ and 3.0, 3.7 KGR, for cross $61 \times 21$, and 37, $34 \mathrm{DKF}$ and 3.4, $2.9 \mathrm{KGR}$ for the cross 19x60. Values of KGR were not significantly different between crosses of early and late selects except for the cross $61 \times 21$ that late select cross had 3.7 , and early select cross has $3.0 \mathrm{~g} . \mathrm{m}^{-2} \cdot \mathrm{d}^{-1}$ KGR. Some researchers [15] reported that they discovered many QTLS in maize related to DKF and KGR, and ultimately they will play an important part on grain yield.

Grain yield:

Grain yield per plant or per unit area is the final output of any grown crop under defined growth variables. Grain yield is the outcome of the different actions and interactions of genetic and environmental parameters, which is represented by the kernels number and its weight [24, 32, 33]. Results of grain yield in Table 3 show that there were significant differences among crosses in grain yield per $\mathrm{m}^{2}$ and per ha.

Several researchers gave some explanations on maize hybrid grain yields that are influenced by epigenetic $[34,35$, $36,37,38]$. Ni et al. [37] reported that changes in gene expression were related with crop growth rate in Arabidopsis thaliana. This could lead to differences in seed yield of plant genotypes. There was an important remarkable note about early and late selects of inbred $\mathrm{Zm} 19$ when crossed to the late inbred tester (Zm21). This cross (19x21) gave lower grain yield of both early and late selects as compared to the same selects crossed with early inbred tester (Zm60). These two crossed (early and late 19x21) gave only 6.642 and $5.621 \mathrm{t}$. $\mathrm{ha}^{-1}$, respectively. This could be due to a different combining ability with that inbred ( $\mathrm{Zm} 21)$. In general, different and genetically diverged inbreds give different combining abilities. It was noticed in data of Table 3 that early selects crossed to early tester ( $\mathrm{Zm60}$ ) had higher grain yield than when crossed with late tester $(\mathrm{Zm} 21)$.

Table 3. Grain yield (kg. $\mathrm{m}^{-2}$ and $\mathrm{t} . \mathrm{ha}^{-1}$ ) of maize crosses of early and late inbred selects obtained from crossing them by two testers (late Zm21 and early Zm60).

\begin{tabular}{|c|c|c|c|c|}
\hline \multirow{3}{*}{ Crosses } & \multicolumn{4}{|c|}{ Selected populations } \\
\hline & Early & Late & Early & Late \\
\hline & \multicolumn{2}{|c|}{ Kg. $\mathbf{m}^{-2}$} & \multicolumn{2}{|l|}{ t. ha $^{-1}$} \\
\hline $19 \times 21$ & 0.66 & 0.56 & 6.642 & 5.621 \\
\hline $32 \times 21$ & 0.77 & 0.74 & 7.691 & 7.370 \\
\hline $51 \times 21$ & 1.02 & 1.00 & 10.214 & 9.952 \\
\hline $61 \times 21$ & 0.99 & 1.09 & 9.901 & 10.899 \\
\hline $19 \times 60$ & 1.05 & 0.82 & 10.516 & 8.188 \\
\hline $32 \times 60$ & 1.03 & 0.92 & 10.307 & 9.158 \\
\hline $51 \times 60$ & 1.00 & 0.94 & 10.029 & 9.386 \\
\hline $61 \times 60$ & 1.02 & 1.00 & 10.199 & 10.024 \\
\hline \multicolumn{5}{|l|}{ lsd } \\
\hline $5 \%$ & 0.21 & & 2.065 & \\
\hline $10 \%$ & 0.17 & & 1.716 & \\
\hline
\end{tabular}

It could be due to the genes of early and late flowering and/or combining ability. Durand et al. [3] stated that flowering time is a complex trait and important in determining yield components, and ultimately grain yield. They reported that they found a series of alleles on one locus of flowering, and this will lead to variations in plant and kernel growth rates that could be related to grain yield.

The differences in growth and yield parameters among hybrids are not necessarily to be governed by DNA only. Epigenetics is pertained to the change in gene expression without a change in DNA nucleotide sequences. Some researchers $[39,40]$ mentioned that siRNAs of 21-24-nt play prime role in novel mutations, some of them are related to late flowering. Shen et al, [18] stated that DNA and siRNA are involved in hybrid vigour. Tollenaar [31] reviewed very good ideas on the role of epigenetics in hybrid performance. They stated that DNA methylation and histone-modification are negatively related with hybrid grain yield. Transposable elements and repeated elements play an important part in regulating gene action. This role will be through activation or silencing of some genes. As a result of that, imprinting will 
take place, and then epimutation appears (in the hybrid) leading to significant and remarkable differences over parental origin.

The results of this article showed that selection for some important traits on inbreds such as flowering could lead to new variations in the selected populations. These variations lead to significant variation in growth parameters of plant and kernel. This will ultimately give significant higher hybrid grain yield. Other traits, such as; ear length, heavier kernel weight, higher ear growth rate, and others may be of highly importance variations in inbred populations that lead to better hybrid performance. Selection for those traits suggests growing large inbred populations (e.g 5000) plants for each inbred. This will increase the probability of variations for better selections.

Molecular genetics results - PCR:

PCR test results shown DNA bands (using primer OPE-13) of the cross $\mathrm{Zm} 19 \mathrm{xZm60}$ selected from early flowering inbreds and the one selected from late flowering inbreds (figure 1 below) and the cross $\mathrm{Zm} 61 \times \mathrm{Zm} 21$ selected from early and late flowering inbreds (figure 2 below).

Bands numbered from 1 to 10 , as we can observe that the

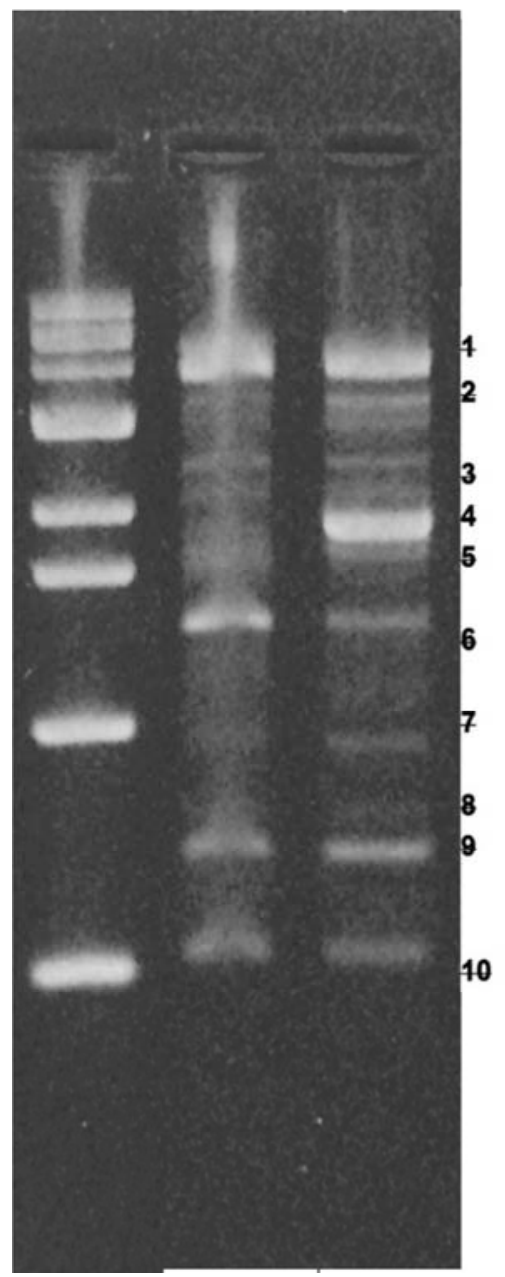

cross of early flowering inbred distinguished oneself on the late flowering inbred by appearing new DNA band (number 2) as well as one largest band (number 4), and third band (number 7), which is less clear of them, besides the band number 6 was decayed in the cross of the early flowering inbred. The cross of early flowering inbred superior the cross of late flowering significantly in grain yield, which could be perhaps due to the gene actions of the these three new bands (figure 1 below).

The differ in the number of the size of DNA bands of the cross $\mathrm{Zm} 61 \mathrm{xZm} 21$ appeared as a result of PCR test using primer OPE-13 is shown in figure 2. In the ten identified bands, it is noted that the cross of the early flowering inbred differed from the late inbred in decaying band number one in the early inbred and appearing new two bands (bands 2 and 8 ), which weren't clear in the cross of the late flowering inbred. The dimension and the degree of the clarity of some bands of both crosses can be noted as well, but they didn't differ significantly in grain yield, but the cross of late flowering inbred gave the highest grain yield among the other crosses of the experiment.

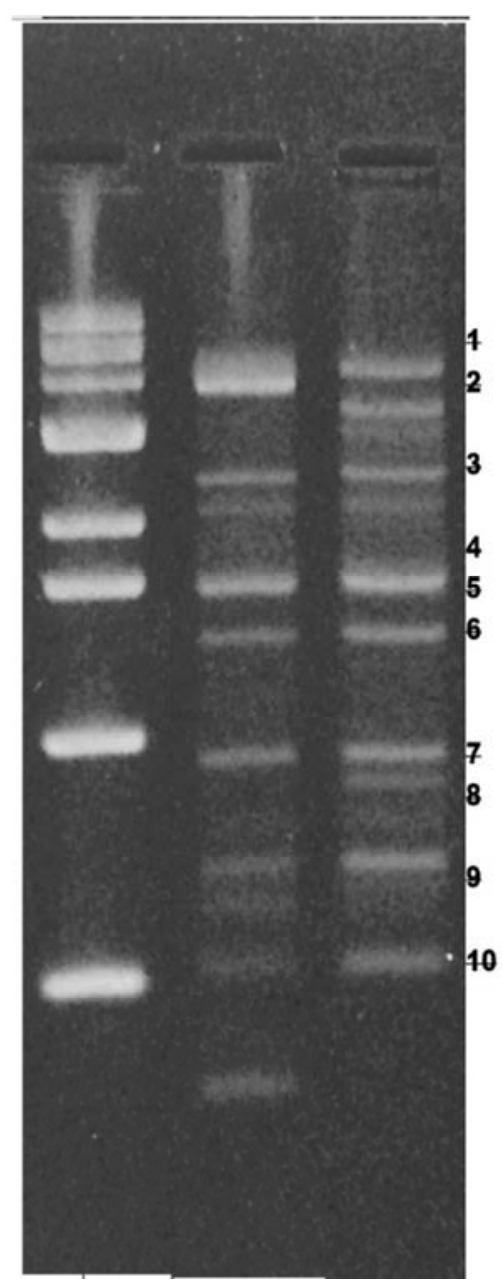

Figure 1. Cross Zm19xZm60 to the right of the reader with the early inbred, in the middle with the late inbred and to the left of the reader the control marker using the primer OPE-13.t (Left).

Figure 2. Cross Zm61xZm21 to the right of the reader with the early inbred, in the middle with the late inbred and to the left of the reader the control marker using the primer OPE-13. (Right). 


\section{Conclusions}

The role of early and late selection on the inbreds was positive is giving crosses of high grain yield, this was due the increasing Days of kernel filling and the high kernel growth rate for some crosses. The growth rate, weight of kernel, and the dry matters assimilation duration of the distinct crosses played significant role in the superiority of the crosses in the grain yield. The Effectiveness of the selection on such inbreds will broaden the genetics base for the breeder as well as increasing the genetic divergence between the mate parents.

\section{Abbreviations}

DKF- Days of Kernel Filling; KGR- Kernel Growth Rate; siRNA- small intervening RNA.

\section{References}

[1] Coelho, C. P., A. P. Costa Netto, J. Colasanti, and A. ChalfunJunior. 2013. A proposed model for the flowering signaling pathway of sugarcane under photoperiodic control. Genetics and Molecular Research 12 (2): 1347-1359.

[2] Colasanti, J., and M. G. Muszynski. 2008. The maize floral transition. Handbook of Maize: Its Biology, Vol 1. Springer Science, New York, p. 41-55.

[3] Durand, E., S. Bouchet, P. Bertin, A. Ressayre, P. Jamin, A. Charcosset, C. Dillmann, and M. Tenaillon. 2012. Flowering time in maize: Linkage and epistasis at a major effect locus. Genetics. 190 (4): 1547-1562.

[4] Brachi, B., N. Faure, M. Horton, E. Flahauw, A. Vazquez, M. Nordborgm J. Bergelson, J. Cuguen, and F. Roux. 2010. Linkage and association mapping of Arabidopsis thaliana flowering time in nature. PLoS Genets. 6 (5): e1000940.

[5] Buckler, E. S., J. B. Holland, P. J. Bradbury, C. B. Acharya, P. J. Brown, C. Browne, E. Ersoz, S. Flint-Garcia, A. Garcia, J. C. Glaubitz, M. M. Goodman, C. Harjes, K. Guill, D. E. Kroon, S. Larsson, N. K. Lepak, H. Li, S. E. Mitchell, G. Pressoir, J. A. Peiffer, M. O. Rosas, T. R. Rocheford, M. C. Romay, S. Romero, S. Salvo, H. S. Villeda, H. S. da Silva, Q. Sun, F. Tian, N. Upadyayula, D. Ware, H. Yates, J. Yu, Z. Zhang, S. Keresovich, and M. D. McMullen. 2009. The genetic architecture of maize flowering time. Science. 325: 714-718.

[6] Chardon, F., B. Virlon, L. Moreau, M. Falque, J. Joets, L. Decousset, A. Murigneux, and A. Charcosset. 2004. Genetic architecture of flowering time in maize as inferred from quantitative trait loci meta-analysis and synteny conservation with the rice genome. Genetics 168: 2169-2185.

[7] Cockram, J., H. Jones, F. J. Leigh, D. O'Sullivan, W. Powell, D. A. Laurie, and A. J. Greenland. 2007. Control of flowering time in temperate cereals: genes, domestication, and sustainable productivity. J. Exp. Bot. 58 (6): 1231-1244.

[8] Xue, W. Y., Y. Z. Xing, X. Y. Weng, Y. Zhao, W. J. Tang, L. Wang, H. J. Zhou, S. B. Yu, C. G. Xu, X. H. Li, and Q. F. Zhang.2008. Natural variation in Ghd7 is an important regulator of heading date and yield potential in rice. Nat.
Genet., 40 (6): 761-767.

[9] Durand, E., M. I. Tenaillon, C. Ridel, D. Coubriche, P. Jamin, S. Jouanne, A. Ressayre, A. Charcosset, and C. Dillman. 2010. Standing variation and new mutations both contribute to a fast response to selection for flowering time in maize inbreds. BMC Evolutionary Biology. 10: 2.

[10] Chardon, F., D. Hourcade, V. Combes, and A. Charcosset. 2005. Mapping of a spontaneous mutation for early flowering time in maize highlights contrasting allelic series at twolinked QTL on chromosome 8. Theor. Appl. Genet. 112 (1): 111 .

[11] Barber, W. T., W. Zhang, H. Win, K. K. Valara, J. E. Dorweiler, M. E. Hudson, and S. P. Moose. 2012. Repeat associated small RNAs vary among parents and following hybridization in maize. PNAS USA. 109 (26): 10444-10449.

[12] Fu, D., M. Xiao, A. Hayward, G. Jiang, L. Zhu, Q. Zhou, J. $\mathrm{Li}$, and M. Zhang. 2015. What is crop heterosis: New insights into an old topic. J. Appl. Genet. 56 (1):1-13.

[13] Fu, J., Y. Cheng, J. Linghu, X. Yang, L. Kang, Z. Zhang, J. Zhang, C. He, X. Du, Z. Peng, B. Wang, L. Zhai, C. Dai, J. $\mathrm{Xu}$, W. Wang, X. Li, J. Zheng, L. Chen, L. Luo, J. Liu, X. Qian, J. Yan, J. Wang, and G. Wang. 2013. RNA sequencing reveals the complex regulatory network in maize kernel. Nat. Commun. 4: 2832.

[14] Chen, Z. J. 2013. Genomic and epigenetic insights into the molecular bases of heterosis. Nat. Rev. Genet. 14 (7):471-482.

[15] Greaves, I. K., M. Groszmann, H. Ying, J. M. Taylor, W. J. Peacock, and E. S. Dennis. 2012. Trans chromosomal methylation in Arabidopsis hybrids. Proc. Natl. Acad. Sci. USA. 109 (9): 3570-3575.

[16] Groszmann, M., I. K. Greaves, Z. I. Albertyn, G. N. Scofield, W. J. Peacock, and E. S. Dennis. 2011. Changes in 24-nt siRNA levels in Arabidopsis hybrids suggest an epigenetic contribution to hybrid vigor. Proc. Natl. Acad. Sci. USA 108 (6): 2617-2622.

[17] Hofmann, N. R. 2012. A global view of hybrid vigor: DNA methylation, small RNAs and gene expression. The Plant Cell. 24 (3): 841.

[18] Shen, H., H. He, J. Li, W. chen, X. Wang, L. Guo, Z. Peng, G. He, S. Zhong, Y. Qi, W. Terzaghi, and X. W. Deng. 2012. Genome-wide analysis of DNA methylation and gene expression changes in two Arabidopsis ecotypes and their reciprocal hybrids. The Plant Cell. 24: 875-892.

[19] Benito, C., A. M. Figueiras, C. Saragoza, F. J. Gallego, and A. de la Pena. 1993. Rapid identification of Triticeae genotypes from single seeds using the polymerase chain reaction. Plant Molecular Biology 21: 181-183.

[20] Williams, J. G., A. R. Kubelik, K. J. Livak, J. A. Rafalski, and S. V. Tingey. 1990. DNA polymorphisms amplified by arbitrary primers are useful as genetic markers. Nucleic Acids Research, 18 (22): 632-6535.

[21] Tollenaar, M., L. M. Dwyer, D. W. Stwart, and B. L. Ma. 2000. "Physiological parameters associated with differences in kernel set among maize hybrids": Physiology and Modeling Kernel Set in Maize. CSSA. Spec. Publ. No. 29, Crop Science Society of American (CSSA) and American Society of Agronomy (ASA), USA, p. 115-130. 
[22] Vanderlip, R. L. 1993. How a Sorghum Plant Develops. Kansan State University. pp 20. http:WWW.oznet. Ksu.edu.

[23] Alvarez Prado, S., B. L. Gambín, A. D. Novoa, D. Foster, M. L. Senior, C. Zinselmeier, M. E. Otegui, and L. Borrás. 2013. Correlation between parental inbred lines and derived hybrid performance for grain filling traits in maize. Crop Sci. 53: $1636-1645$.

[24] Alvarez Prado, S., C. G. López, M. L. Senior, and L. Borrás. 2014. The genetic architecture of maize (Zea mays L.) kernel weight determination. Crop Sci. 9: 1611-1621.

[25] Sadras, V. O. 2007. Evolutionary aspects of the trade-off between seed size and number in crops. Field Crops Research. 100 (2-3): 125-138.

[26] Bingham, I. J., J. Blake, M. J. Foulkes, and J. Spink. 2007. Is barley yield in the UK sink limited? II. Factors affecting potential grain size. Field Crops Res. 101: 212-220.

[27] Rondanini, D. P., R. Savin, and A. J. Hall. 2007. Estimation of physiological maturity in sunflower as a function of fruit water concentration. Eur. J. of Agron. 26 (3): 295-309.

[28] Borrás, L., and B. L. Gambín. 2010. Trait dissection of maize kernel weight: Towards integrating hierarchical scales using a plant growth approach. Field Crops Res. 118: 1-12.

[29] El-Shouny, K. A., O. H. El-Baguary, K. I. M. Ibrahim and S. A. Al-Ahmad. 2005. Correlation and path coefficient analysis in four yellow maize crosses under two planting dates. ArabUniv. J. Agri. Sci. ‘13 (2): 327-339.

[30] Borrás, L., C. Zinselmeier, M. L. Senior, M. E. Westgate, and M. G. Muszynski. 2009. Characterization of grain-filling patterns in diverse maize germplasm. Crop Sci. 49: 999-1009.

[31] Tollenaar, M., and E. A. Lee. 2011. Strategies for enhancing grain yield in maize. Plant Breeding Reviews. 34: 37-83.

[32] Elsahookie, M. M. 2007. An Introduction to Plant Molecular Biology. $2^{\text {nd }}$ edn.(in Arabic), Ministry of Higher Education and Scientific Research, Univ. of Baghdad, Baghdad, Iraq, pp. 190.

[33] Slafer, G. A. 2003. Genetic basis of yield as viewed from a crop physiologist's perspective. Ann. Appl. Biol. 142 (2): $117-128$.

[34] Cubas, P., C. Vincent, and E. Coen. 1999. An epigenetic mutation responsible for natural variation in floral symmetry. Nature 401:157-161.

[35] He, X. J., T. Chen, and J. K. Zhu. 2011. Regulation and function of DNA methylation in plants and animals. Cell Res. 21: $442-465$.

[36] Manning, K., M. Tör, M. Poole, Y. Hong, A. J. Thompson, G. L. King, J. J. Giovannoni, and G. B. Seymour. 2006. A naturally occurring epigenetic mutation in a gene encoding an SBP-box transcription factor inhibits tomato fruit ripening. Nat. Genet. 38: 948-952.

[37] Ni, Z., E. D Kim, M. Ha, E. Lackey, J. Liu, Y. Zhang, Q. Sun, and Z. J. Chen. 2009. Altered circadian rhythms regulate growth vigour in hybrids and allopolyploids. Nature. 457 (7227): 327-331.

[38] Shindo, C., C. Lister, P. Crevillen, M. Nordborg, and C. Dean. 2006. Variation in the epigenetic silencing of FLC contributes to natural variation in Arabidopsis vernalization response. Genes Dev. 20 (22): 3079-3083.

[39] Arteaga-Vazquez, M., L. Sidorenkoa, F. A. Rabanala, R. Shrivistavac, K. Nobutac, P. J. Greenc, B. C. Meyersc, and V. L. Chandlera. 2010. RNA-mediated trans-communication can establish paramutation at the b1 locus in maize. PNAS 107: 12986-12991.

[40] Dorweiler, J. E., C. C. Carey, K. M Kubo, J. B. Hollick, J. L. Kermicle, and V. L. Chandler. 2000. Mediator of paramutation 1 is required for establishment and maintenance of paramutation at multiple maize loci. Plant Cell 12: 21012118 . 